\title{
Greek Young Children's Engagement with Media in the Home: Parents' and Children's Perspectives
}

\author{
Anastasia G. Stamou ${ }^{1}$, Katerina Maroniti' ${ }^{1} \&$ Dimitris Schizas ${ }^{2}$ \\ ${ }^{1}$ Department of Early Childhood Education, University of Western Macedonia, Florina, Greece \\ ${ }^{2}$ School of Ecology, Department of Biology, Aristotle University of Thessaloniki, Greece \\ Correspondence: Anastasia G. Stamou, Department of Early Childhood Education, University of Western Macedonia, \\ Florina, 53100, Greece.
}

Received: October 30, 2014 Accepted: November 17, $2014 \quad$ Available online: November 28, 2014

doi:10.11114/smc.v2i2.572

URL: http://dx.doi.org/10.11114/smc.v2i2.572

\begin{abstract}
Recent developments in literacy studies suggest that everyday media experiences of children should be included and inform school literacy. In light of this, in the present study, we map children's access and patterns of use, as well as children's and parents' stance and views on media. From the analysis of interviews with children and questionnaires with parents, it was made clear that children have rich media experiences in the home, having access to print, screen entertainment and digital media, whereas the presence of video games in Greek homes is more limited compared with other countries. Parents seem to be affected by the 'moral panics' often surrounding young children's use of media. Moreover, our study indicated that families with a more privileged social and educational background seem to be more oriented to print and digital media than families with a lower social status. In contrast, families of lower social and educational background tend to be more oriented to screen entertainment media. On the other hand, some significant differences with respect to the children's gender were disclosed, which seem to be linked to the social expectations and the distinct social roles of what means to 'be a girl' and 'a boy'. In conclusion, we suggest that a study including both the perspectives of parents and children on the latter's media activities in the home can better address the limitations of (self)-reporting and complement observational studies of literacy practices.
\end{abstract}

Keywords: out-of-school literacy practices, media education, school literacy, Greece

\section{Introduction}

\subsection{Introductory Remarks}

The field of 'New Literacy Studies' (e.g. Gee, 2004; Street, 1993) has given prominence to the study of children's literacy practices in the home, which are related to media, by acknowledging new types of literacy beyond print (school) literacy. Giving emphasis on the complexity and richness of literacy in out-of-school contexts and offering recognition of the new kinds of learning occurring outside school, it is suggested that these everyday sociocultural experiences of children should be included and inform school literacy. In fact, it has been supported that the use of media at school, by offering recognition of the things children value, helps them to be more actively involved in the class and to understand more easily abstract concepts (Duff, 2004). Furthermore, several positive effects on children's early literacy skills have been documented, such as letter and word recognition (Ball \& Bogatz, 1970), as well as narrative skills development (Linebarger \& Piotrowski, 2009). On the other hand, seen as the missing link between the teacher and the student script (Gutiérrez, Baquedano-Lopez, \& Tejeda, 2000), media could redress the dislocation between home and school literacy, which is often detected (e.g. Marsh, 2003).

New Literacy Studies have been criticized for over-emphasizing the distinction between the 'in-school' and the 'out-of-school', and thus failing to see that these spaces are not so isolated from one another, since children may also engage in school-like activities at home and non-school-like ones at school (Hull \& Schultz, 2001). Nevertheless, it has acknowledged the central role that media play in contemporary childhoods. More importantly, this research strand has triggered off a number of relevant studies in the last years, which have disclosed different patterns of media access and use at home, mostly depending on social arrangements of time and space and on cultural norms and values (e.g. Ofcom., 2013; Livingstone \& Bovill, 1999; Marsh et al., 2005). 
In light of this, in the present study, we aim to explore Greek young children's (5-7 years old) engagement in media activities in the home. In particular, we wish to map children's access and patterns of use, as well as children's and parents' stance and views on print (books, comics, magazines), screen entertainment (television, DVD, video games) and digital media (computer), through an account of children's and parents' perspectives. In the last years, there have been a number of studies, especially in the UK, and mostly in the framework of large-scale research projects, aiming to chart children's and young people's media literacy practices.

Most of these studies have focused on children above five years old (Ofcom., 2013; Livingstone \& Bovill, 1999), while there are fewer studies on younger children, such as infants and pre-schoolers (Marsh et al., 2005; Rideout, Vandewater, \& Wartella 2003). Two other recent studies have explored children's aged 6-18 years old access to and use of 'screens', such as television, DVD player, cell phone, computer and video games, in Spain (Bringué \& Sádaba, 2009a) and Ibero-America (Bringué \& Sádaba, 2009b), by adopting a cross-national perspective. Given the fact that children are now participating in online literacy practices at a younger and younger age, there is an amount of studies exploring, in particular, children's engagement with digital media and online activities (e.g. Haddon \& Livingstone, 2012; Livingstone \& Bober, 2005). More recent studies have detected an increase in internet use by very young children such as pre-schoolers, so that they usually participate in sites which are not suitable and intended for their age (Holloway, Green, \& Livingstone, 2013). On the other hand, the most recent study of Mascheroni \& Cuman (2014) has compared children's (9-16 years old) use of new media and technologies in four European countries: Denmark, Italy, Romania and the UK.

Relevant research in Greece is scanty and concerns only elementary school children (Stamou, Griva, \& Tsioulis, 2013; Tsami, Archakis, Fterniati, Papazachariou, \& Tsakona, 2014), while there are few studies with a particular focus on children's and young people's digital and online practices (Koutsogiannis, 2011; Tsaliki \& Chronaki, 2012). With respect to internet use, compared with other European countries, Greece is characterized as a 'lower use, lower risk' country, along with Italy, France, Germany, Austria, Belgium and Hungary (Haddon \& Livingstone, 2012). Thus, Greek children exhibit fewer digital skills, but $66 \%$ of them access the internet on their mobiles, well above the European average (22\%).

From a methodological perspective, a great deal of research in the field is based on (self)-reporting of children and/or their parents, and thus more observational studies exploring how children engage in media activities in their everyday life are proposed to be conducted (Buckingham, 2004). In the present study, we also adopt research tools of (self)-reporting, such as questionnaires and interviews. By acknowledging, however, the limitations of a study relying on what people are saying as doing rather than on observations of what they are actually doing, we focus on the perspectives of both children and their parents, treating the two groups not only as offering complementary accounts, as it is usually the case, but also as providing contradictory reports (e.g. under- and over-reporting) on children's media activities. In what follows, the aims and scope of the present study are outlined in more detail.

\subsection{Aims and Scope}

In the present study, we seek to explore the following:

-Which media have children access to? $\bullet$ What are children's patterns of media use? $\bullet$ What is children's stance towards media? $\bullet$ What do parents think about the educational opportunities afforded by media? • Are there any differences in children's media access and use as well as in children's and parents' attitudes and thoughts about media in relation to the parents' social and educational background and the children's gender?

More specifically, children's media access will be explored in respect of the ways in which their parents shape media literacy environment at home, namely what media their family owns, what media children personally own in their bedroom, what media their parents use at home and what book reading and outdoor spectacle opportunities (e.g. theater, movies) their parents offer to them. Relevant research shows that children's media access is not only an issue of available financial resources, but it also relates to parents' educational and cultural resources, as well as to their values and beliefs about child-rearing (Buckingham, 2004). In particular, whether parents provide a 'media-rich', a 'media-poor', or a 'screen entertainment' bedroom (Livingstone \& Bovill, 1999) to their children (e.g. whether children should have a television set in their room) is more a reflection of parents' broader ideas about the nature of family life than an issue of income.

Since the relationship between media access and use is not straightforward, it makes sense to also unveil children's media use at home. According to the 'domestication approach', which refers to the ways (digital) media are contextualized into people's lives and what symbolic meanings they are attached to (e.g. Haddon, 2011; Silverstone \& Haddon, 1996), two central processes of domestication are the daily (the so-called 'objectification') and spatial (the so-called 'incorporation') distribution of media activities in the home. Specifically, in our case, objectification refers to how children fit media into daily life, namely how they divide their leisure time among different media, charting a 
'leisure timetable' (Livingstone \& Bovill, 1999). On the other hand, incorporation involves the spatial patterns of children's media use, which will further reveal the meanings and practices accompanying its daily use. The home is divided into two core domains: spaces which are specific to the child (e.g. bedroom) and spaces which are shared by all family members and form the wider home environment (e.g. living room, kitchen). It has been found than many of the texts in the domain specific to the child relate to media, showing their centrality to children's lives (Marsh, 2003). Furthermore, media use also involves children's preferences of concrete media content (e.g. favorite TV programs, movies, books, comics). Research has indicated that more differences exist in content preferences in relation to the gender than to the social background of children (Livingstone \& Bovill, 1999).

Children's stance towards media will be examined with respect to their immersion in media at home. According to the domestication approach, this is the 'conversion' process, namely how (digital) media use is related to the construction of identity (Haddon, 2011). It has been supported that children live in a media-saturated world, in which texts are intertextually connected with each other. For instance, TV characters may also appear in children's books, toys or clothes (Marsh \& Milliard, 2000). Hence, we will explore children's favorite popular cultural heroes and ownership of media icons. Parents have indicated their children's obsession with media icons (Marsh et al., 2005), since it is through these icons that children seem to construct their identity and build their social relationships with the other children (Marsh, 2005).

Finally, parents' views on the educational role of media will be studied in order to detect whether their practices in the home (i.e. shaping and regulation of their children's media access and use) reflect or not their ideas about media. Relevant research has shown that parents generally hold favorable ideas about the role of media in their children's lives and their literacy development (e.g. Marsh et al., 2005; Rideout et al., 2003). However, they also tend to express some concerns and worries about media content (e.g. violence, consumerist values) (Livingstone \& Bovill, 1999; Ofcom., 2013).

\section{Method}

Data collection was made through two complementary research tools: semi-structured interviews with young children aged 5-7 years old and questionnaires with their parents. Specifically, 455 children ( 235 boys and 220 girls) attending pre-school and the first two grades (Grade 1 and 2) of elementary school (aged 6 years old on average) participated in the study. Having access to school records, the job of children's parents was recorded for each interviewed child. For the purposes of the present study, a distinction was made between 'low' (e.g. employees, technicians) and 'high autonomy professions' (e.g. educators, business owners, lawyers, engineers), depending on the freedom an individual has in carrying out work, namely the ability to control the timing of work, to control how work is performed, and to make decisions at work (Morgeson, Delaney-Klinger \& Hemingway, 2005). Since this distinction normally also means a different social status, salary and educational background on the part of the working parent, it seems to be crucial for children's sociolinguistic and literacy development (Hasan, 1989). In our sample, $51 \%$ of the children had a father of low autonomy profession and $49 \%$ a father of a high autonomy profession. $64 \%$ of the children had a mother with a low autonomy job and $36 \%$ of them had a mother with a high autonomy job (see Figure 1).

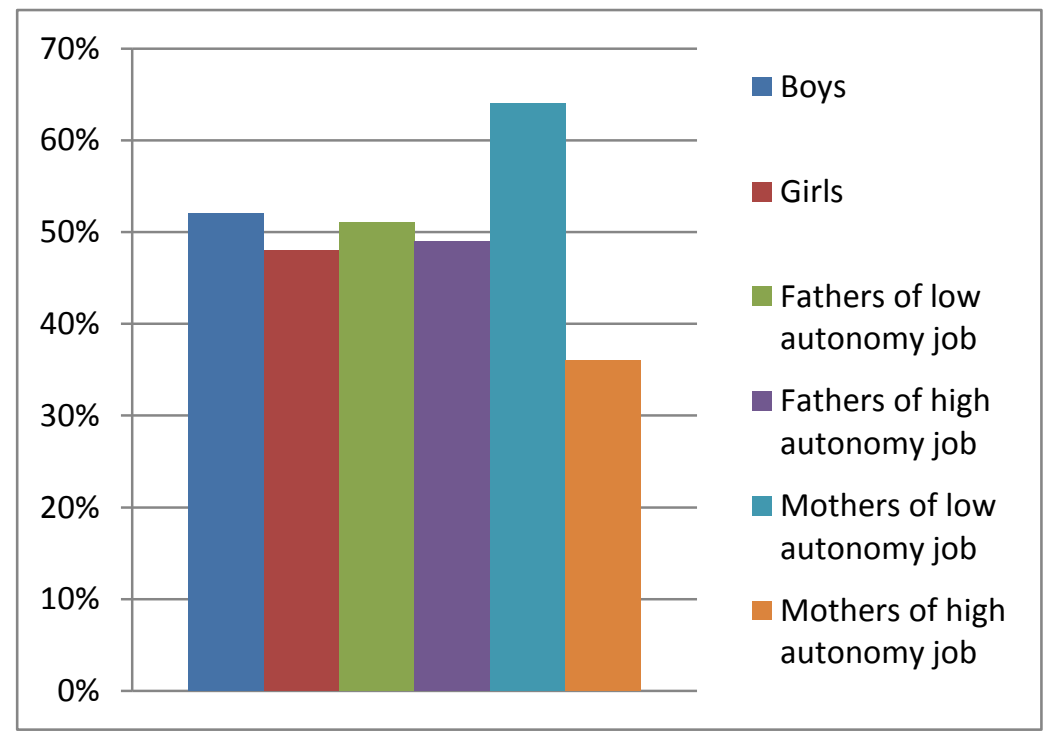

Figure 1. The sample of the children participated in the study

Moreover, 373 parents/ carers whose child was interviewed were given a questionnaire. 302 of them were mothers and 
only 71 were fathers, reflecting the gendered patterns of parental involvement in schooling (Reay, 1998). 57\% of the participants responded to do a low autonomy job and $43 \%$ of them to do a high autonomy job. Furthermore, $2 \%$ of the parents reported to be elementary school graduates, $59 \%$ of them to be high school graduates and $39 \%$ of the parents reported to hold a university degree (see Figure 2).

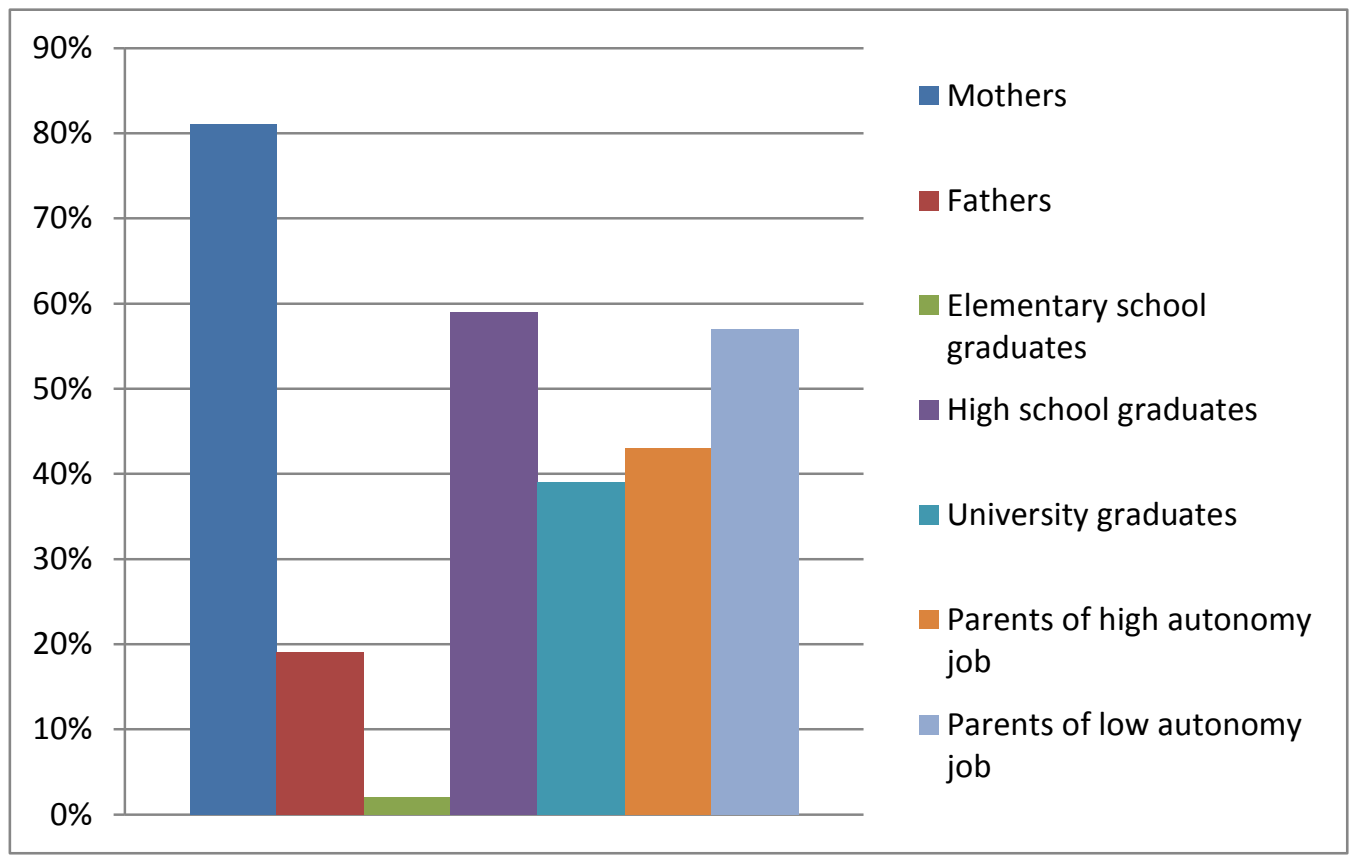

Figure 2. The sample of the parents participated in the study

The construction of parents' questionnaire, according to which children's interview questions were also made, was substantially based on a similar study of Marsh et al. (2005) on pre-school children's (of 41 months on average) media access and use and parental views in the UK. Most of the questions were closed, but some few open questions were also included. In particular, the questionnaire consisted of the following sections: children's media access (family and children's ownership of media, parents' media habits, children's access to book reading and outdoor spectacles), children's patterns of media use (temporal and spatial distribution of leisure and media activities in the home, children's reading and television preferences) and children's and parents' stance and views on media (children's immersion in media, parents' views on the educational opportunities of media for their children).

Both interview and questionnaire data were analyzed though various statistical techniques. In particular, we applied chi-square test and multivariate log-linear analysis on discrete categorical data, whereas we used Spearman correlation and Principal Component Analysis (PCA) for the interpretation of the data measured on an ordinal and an interval scale, respectively. Most of the statistical analyses were conducted using the SPSS package. Statistica software was used for the conduct of PCA.

\section{Results}

\subsection{Children's Access to Media}

\subsubsection{Family Ownership of Media}

According to parents, children are exposed to a rich media environment in the home, consisting of printed texts, as well as screen entertainment (television: 99\%, DVD: 93\%) and digital media appliances (computer: 85\%, internet connection: $82 \%$ ) (Table 1). However, most families are oriented to traditional printed material (books: $96 \%$ ) rather than to texts from popular culture (newspapers/ comics/ magazines: 64\%). On the other hand, console games seem to be less widespread among Greek households $(27 \%)$. Moreover, according to chi-square test analysis, the presence of internet connection in the family is positively correlated with the presence of newspapers, comics and magazines $\left(\mathrm{X}^{2}=7.190\right.$, $\mathrm{df}=1, \mathrm{p}=0.007$, Phi=0.139). This means that children's access to digital media does not deter them from being also exposed to printed material, but a home open to new technologies seems to be 'media rich' in general. Additionally, from children's responses, it emerges that only $24 \%$ of the families own a single television set, while $51 \%$ of the families own two television sets and $24 \%$ of the families possess more than two television sets in the home. On the other hand, more children reported to own console games compared with parents (38\% vs. 27\%, respectively). 
Table 1. Ownership of media in the home (parents' responses)

\begin{tabular}{ll}
\hline Television set & $99 \%$ \\
Books & $96 \%$ \\
DVD player & $93 \%$ \\
Computer & $85 \%$ \\
Internet connection & $82 \%$ \\
Newspapers/ comics/ magazines & $64 \%$ \\
Video game machine & $27 \%$ \\
\hline
\end{tabular}

Chi-square test and multivariate log-linear analysis indicated several significant differences in the family ownership of media with respect to parents' educational and social background as well as to children's gender. Specifically, statistical analysis of both parents' and children's responses revealed that the possession of digital media (computer, internet connection) is tightly knitted to the social profile of parents. Hence, more parents doing a high autonomy job (93\%) $\left(\mathrm{X}^{2}=8.140, \mathrm{df}=1, \mathrm{p}=0.04, \mathrm{Phi}=0.154\right)$ reported to own a computer than parents who do a low autonomy job $(82 \%)$. Similarly, more parents with a high autonomy job $(90 \%)\left(\mathrm{X}^{2}=6.861, \mathrm{df}=1, \mathrm{p}=0.04, \mathrm{Phi}=0.141\right)$ have an internet connection in the home than parents who make a low autonomy job (80\%). Additionally, more children whose father $(91 \%)\left(X^{2}=5.192, d f=1 \mathrm{p}=0.02, \mathrm{Phi}=0.111\right)$ or mother $(93 \%)\left(\mathrm{X}^{2}=7.067, \mathrm{df}=1 \mathrm{p}=0.04, \mathrm{Phi}=0.129\right)$ does a high autonomy job responded to have a computer in the home than children with a father $(84 \%)$ or mother (84\%) doing a low autonomy job. In a similar vein, more children with a father $(87 \%)\left(\mathrm{X}^{2}=7.148, \mathrm{df}=1 \mathrm{p}=0.05\right.$, Phi=0.130) or mother $(91 \%)$ $\left(\mathrm{X}^{2}=14.146, \mathrm{df}=1 \mathrm{p}=0.00, \mathrm{Phi}=0.182\right)$ doing a high autonomy job responded to have internet connection in the home than children with a father $(77 \%)$ or mother $(76 \%)$ doing a low autonomy job. Furthermore, according to multivariate log-linear analysis, a lack of computers at home is correlated with parents' elementary (Estimate $=3.498$, Std. Error=0.810, $\mathrm{Z}=4.317, \mathrm{p}=0.00$ ) or high school education (Estimate=1.020, Std. Error=0.367, Z=2.783, p=0.05).

On the other hand, families with a more privileged social background seem to be more oriented to print media, while families with a lower social status seem to be more engaged with screen entertainment media. Thus, more parents doing a high autonomy job $(96 \%)\left(\mathrm{X}^{2}=5.012, \mathrm{df}=1, \mathrm{p}=0.03\right.$, Phi=0.121) reported to own more newspapers, comics and magazines in the home than parents who do a low autonomy job (60\%). Similarly, a lack of books and newspapers, comics and magazines in the home was correlated respectively with parents' elementary (Estimate $=2.543$, Std. Error=0.739, $\mathrm{Z}=3.438, \mathrm{p}=0.001$ ) or high school education (Estimate=0.817, Std. Error=0.238, Z=3.441, p=0.0001). In contrast, more children with a mother doing a low autonomy job $(91 \%)\left(\mathrm{X}^{2}=6.457, \mathrm{df}=1 \mathrm{p}=0.01\right.$, Phi=-0.123) responded to own a DVD player than children with a mother doing a high autonomy job (83\%). Finally, more boys (46\%) $\left(\mathrm{X}^{2}=15.601, \mathrm{df}=1 \mathrm{p}=0.00, \mathrm{Phi}=-0.185\right)$ reported to own a video game machine than girls $(28 \%)$.

\subsubsection{Children's Ownership of Media}

Following parents' responses, in the majority of children's bedrooms, printed material prevails (books/ comics/ magazines: 90\%), while their bedrooms are less equipped with screen entertainment (television set: $23 \%$, DVD player: 16\%, console games: $4 \%$ ) or digital media (computer: 12\%; see Table 2). In contrast to parents, $7 \%$ of the children reported to have a television set in their room and $3 \%$ to own a computer. According to multivariate log-linear analysis, a lack of printed material in children's bedroom is correlated with parents' elementary school education (Estimate=2.182, Std. Error=0.722, Z=3.023, p=0.003). On the other hand, chi-square test showed that more children whose father does a low autonomy job $(10 \%)\left(\mathrm{X}^{2}=7.955, \mathrm{df}=1 \mathrm{p}=0.05, \mathrm{Phi}=-0.188\right)$ reported to have a television set in their bedroom than children with a father doing a high autonomy job (3\%). Furthermore, 93\% of the children responded to possess their own books, but fewer children seem to personally possess magazines (44\%) and comics (29\%). Chi-square test revealed that more boys $(36 \%)\left(\mathrm{X}^{2}=12.073, \mathrm{df}=1 \mathrm{p}=0.01\right.$, Phi=-0.163) than girls $(21 \%)$ reported to possess their own comics.

Table 2. Ownership of media in children's bedroom (parents' responses)

\begin{tabular}{ll}
\cline { 2 - 2 } Books/ comics/ magazines & $90 \%$ \\
Television set & $23 \%$ \\
DVD player & $16 \%$ \\
Computer & $12 \%$ \\
Video game machine & $4 \%$ \\
\hline
\end{tabular}

\subsubsection{Parents' Media Habits}

The majority of children reported that their parents read newspapers (64\%) and magazines (66\%). However, chi-square test showed that more children with a father $(70 \%)\left(X^{2}=3.910, \mathrm{df}=1 \mathrm{p}=0.05, \mathrm{Phi}=0.096\right)$ or mother $(75 \%)\left(X^{2}=9.710\right.$, $\mathrm{df}=1 \mathrm{p}=0.02$, Phi=0.151) doing a high autonomy job responded that their parents read newspapers than children whose 
father $(30 \%)$ or mother $(60 \%)$ does a low autonomy job.

Regarding their parents' TV preferences, $42 \%$ of the children responded that their parents watch the news, $28 \%$ that they watch some series and $20 \%$ some film. Few children responded that their parents watch TV commercials (7\%) or they did not know what their parents watch (8\%). Chi-square test revealed that more children with a father doing a low autonomy job (24\%) $\left(\mathrm{X}^{2}=4.772, \mathrm{df}=1 \mathrm{p}=0.03\right.$, Phi=-0.106) reported that their parents watch films on television than children with a father doing a high autonomy job (16\%).

Regarding computer use, $51 \%$ of the children responded that all family members use a computer in the home. However, $15 \%$ of the children reported that a computer is used only by the child's father, $11 \%$ only by his/her parents and $5 \%$ only by the child's mother. On the other hand, chi-square test indicated that the prominence or not of digital media in the family environment is associated with the parents' social status. Hence, more children whose father does a high autonomy job $(58 \%)\left(\mathrm{X}^{2}=7.759, \mathrm{df}=1 \mathrm{p}=0.05\right.$, $\left.\mathrm{Phi}=0.136\right)$ responded that that all the family uses a computer in the home than children with a father doing a low autonomy job $(45 \%)$.

\subsubsection{Children's Access to Book Reading and Outdoor Spectacles}

According to children's responses, book reading seems to be a popular activity in their families, since $93 \%$ of them reported to be often read some book. However, this seems to be an activity made mostly by mothers (46\%), less by both mothers and fathers $(22 \%)$ or some other person $(10 \%)$, whereas very few children reported to be read some book by their father only $(5 \%)$. Interestingly, chi-square test showed that more girls $(51 \%)\left(\mathrm{X}^{2}=4.566, \mathrm{df}=1 \mathrm{p}=0.03, \mathrm{Phi}=0.100\right)$ than boys $(41 \%)$ reported to be read some book by their mother, and conversely, more boys $(7 \%)\left(X^{2}=7.350, \mathrm{df}=1\right.$ $\mathrm{p}=0.001$, Phi=-0.127) than girls $(2 \%)$ reported to be read some book by their father.

Regarding children's access to outdoor spectacles, only $40 \%$ of the parents reported to go sometimes their children to the theater, while $49 \%$ responded that they sparingly or never go to the theater with their children (Table 3 ). In contrast, $46 \%$ of the parents reported to go often to the movies with their children and $44 \%$ reported to go sometimes with them to the movies. Interestingly, Spearman correlation revealed a high correlation between parents' response of going often their children to the theater with their response of going often with them to the movies ( $\mathrm{rho}=0.538602, \mathrm{p}=0.001, \mathrm{~N}=368$ ). From their point of view, $64 \%$ and $63 \%$ of the children responded to go often to the movies and to the theater with their family, respectively.

Table 3. Children's access to the theater and the movies (parents' responses)

\begin{tabular}{lccc}
\hline You go your child to the... & Often & Sometimes & Rarely/ Never \\
\hline Theater & $11 \%$ & $40 \%$ & $49 \%$ \\
Movies & $46 \%$ & $44 \%$ & $10 \%$ \\
\hline
\end{tabular}

Chi-square test indicated significant differences in the children's access to the theater and the movies with respect to their parents' educational and social background. Specifically, more parents doing a low autonomy job (56\%) $\left(\mathrm{X}^{2}=13.365, \mathrm{df}=2, \mathrm{p}=0.01, \mathrm{Phi}=0.198\right)$ reported to go rarely/ never to the theater with their children than parents who do a high autonomy job (40\%). Moreover, parents' responses of going rarely/ never to the theater (Estimate $=1.597$, Std. Error $=0.396, \mathrm{Z}=4.032, \mathrm{p}=0.000$ ) or of going sometimes to the theater (Estimate=2.182, Std. Error=0.853, $\mathrm{Z}=0.397$, $\mathrm{p}=0.03$ ) were correlated with their being high school graduates. In a similar vein, more children with a mother doing a high autonomy job $(75 \%)\left(\mathrm{X}^{2}=10.160, \mathrm{df}=1 \mathrm{p}=0.01\right.$, Phi=0.154) reported to go to the theater than children with a mother doing a low autonomy job (59\%). On the other hand, more parents with a low autonomy job $(49 \%)\left(X^{2}=7.228\right.$, $\mathrm{df}=2, \mathrm{p}=0.03$, Phi=0.146) responded that they rarely/ never go their children to the movies than parents with a high autonomy job (43\%). Similarly, more children with a mother doing a high autonomy job $(71 \%)\left(X^{2}=3.976, d f=1\right.$, $\mathrm{p}=0.05$, Phi=0.096) reported to go to the movies than children with a mother doing low autonomy job $(61 \%)$.

\subsection{Children's Patterns of Media Use}

\subsubsection{Temporal Distribution of Leisure and Media Activities in the Home}

According to parents, the daily 'leisure timetable' (Livingstone \& Bovill, 1999: 32) of children is mostly divided among drawing/ writing, playing with toys in the home, television watching and book reading (Table 4). In contrast, DVD watching, outdoor play, computer use, and especially, video game playing are less popular daily activities among children. 
Table 4. Daily patterns of leisure and media activities

\begin{tabular}{lcccc}
\hline $\begin{array}{l}\text { How much time, on average, does your child spend on these } \\
\text { activities in a typical day? }\end{array}$ & $\begin{array}{c}1-2 \\
\text { hours }\end{array}$ & $\begin{array}{c}3-4 \\
\text { hours }\end{array}$ & $\begin{array}{c}\text { More than } 4 \\
\text { hours }\end{array}$ & $\begin{array}{c}\text { Rarely/ } \\
\text { Never }\end{array}$ \\
\hline Being read a book & $79 \%$ & $1 \%$ & $1 \%$ & $19 \%$ \\
Drawing/ Writing & $74 \%$ & $17 \%$ & $3 \%$ & $6 \%$ \\
Watching television & $65 \%$ & $15 \%$ & $2 \%$ & $18 \%$ \\
Playing inside & $57 \%$ & $29 \%$ & $12 \%$ & $2 \%$ \\
Watching a DVD & $55 \%$ & $4 \%$ & $0 \%$ & $41 \%$ \\
Playing outside & $54 \%$ & $15 \%$ & $5 \%$ & $25 \%$ \\
Using a computer & $39 \%$ & $2 \%$ & $1 \%$ & $58 \%$ \\
Playing video games & $11 \%$ & $1 \%$ & $1 \%$ & $87 \%$ \\
\hline
\end{tabular}

To explore possible associations among the aforementioned parents' responses, the data were further analyzed, employing PCA. PCA indicated that three factors explained about 53\% of the total variance (Table 5). The first factor explains $20.5 \%$ of the total data variability and has strong loadings for items expected to measure both traditional and active leisure activities of children (playing, drawing/ writing). The second factor explains $17.6 \%$ of the total variance and is loaded on items concerning screen entertainment (television and DVD watching) and digital (computer use) media activities. Finally, the third factor accounts for $15.4 \%$ of the total variance and is marked by high loadings on items that concern passive leisure activities, that is, activities that entail a passive role on the part of children (being read a book).

Table 5. Principal component analysis of parents' responses about the daily patterns of leisure and media activities of their children

\begin{tabular}{|c|c|c|c|}
\hline $\begin{array}{l}\text { How much time, on average, does your child } \\
\text { spend on these activities in a typical day? }\end{array}$ & Factor 1 & Factor 2 & Factor 3 \\
\hline Being read a book & -0.528289 & -0.179819 & 0.634825 \\
\hline Drawing/ Writing & -0.655810 & -0.273704 & 0.173394 \\
\hline Watching television & 0.212504 & -0.587949 & -0.387113 \\
\hline Playing inside & -0.548361 & -0.218183 & -0.466463 \\
\hline Watching a DVD & 0.045443 & -0.548221 & -0.211472 \\
\hline Playing outside & -0.547409 & 0.103956 & -0.484627 \\
\hline Using a computer & 0.291508 & -0.642782 & 0.002259 \\
\hline Expl. Var & 1.441732 & 1.225059 & 1.080101 \\
\hline Prp. Totl & 0.205962 & 0.175008 & 0.154300 \\
\hline
\end{tabular}

Chi-square test and multivariate log-linear analysis revealed some significant differences in the daily patterns of children's leisure and media activities in respect of parents' educational and social profile, since less privileged families seem to be more engaged with screen entertainment media and outdoor leisure activities. Specifically, more parents doing a high autonomy job $(23 \%)\left(\mathrm{X}^{2}=8.001, \mathrm{df}=3, \mathrm{p}=0.05, \mathrm{Phi}=0.145\right)$ reported that their children rarely/ never watch television than parents with a low autonomy job (14\%). Additionally, more parents doing a low autonomy job (55\%) $\left(\mathrm{X}^{2}=10.818, \mathrm{df}=3, \mathrm{p}=0.01, \mathrm{Phi}=0.198\right)$ reported that their children play outside three to four hours per day than parents with a high autonomy job (52\%). Similarly, parents with an elementary school education did not report that their children rarely/never play video games (Estimate=-4.604, Std. Error=1.721, Z=-2.675, p=0.007).

\subsubsection{Spatial Distribution of Leisure and Media Activities in the Home}

According to parents' responses, playing (74\%) and book reading (66\%) are activities which mostly take place in spaces specific to the child (Table 6). Conversely, television (84\%) and DVD watching (67\%), as well as computer use (47\%) are activities mainly occurring in spaces which are shared by other family members in the wider home environment. Drawing/ writing takes place in both children's room (59\%) and the rest of the house (52\%). On the other hand, if we compare parents' responses about their children doing rarely/ never the same leisure and media activities between Table 4 and Table 6 , it becomes evident that there are differences in their responses. Specifically, when parents report the daily patterns of their children's activities tend to over-report that their children rarely/ never watch television in comparison with their responses when they determine the spatial distribution of this activity (18\% in Table 4 vs. $8 \%$ in Table 6 ). The same happens also with DVD watching (41\% in Table 4 vs. $16 \%$ in Table 6$)$, computer use (58\% in Table 4 vs. $37 \%$ in Table 6), book reading (19\% in Table 4 vs. $4 \%$ in Table 6) and video games ( $87 \%$ in Table 4 vs. $73 \%$ in Table 6). 
Table 6. Spatial distribution of leisure and media activities

\begin{tabular}{lccc}
\hline $\begin{array}{l}\text { Where does your child do these activities most of the } \\
\text { time? }\end{array}$ & $\begin{array}{c}\text { Children's } \\
\text { room }\end{array}$ & $\begin{array}{c}\text { Living room/ Other } \\
\text { room }\end{array}$ & $\begin{array}{c}\text { Rarely/ } \\
\text { Never }\end{array}$ \\
\hline Playing inside & $74 \%$ & $39 \%$ & $1 \%$ \\
Being read a book & $66 \%$ & $37 \%$ & $4 \%$ \\
Drawing/ Writing & $59 \%$ & $52 \%$ & $3 \%$ \\
Watching a DVD & $14 \%$ & $67 \%$ & $16 \%$ \\
Using a computer & $10 \%$ & $47 \%$ & $37 \%$ \\
Watching television & $9 \%$ & $84 \%$ & $8 \%$ \\
Playing video games & $5 \%$ & $17 \%$ & $73 \%$ \\
\hline
\end{tabular}

Chi-square test and multivariate log-linear analysis revealed several significant differences in the (spatial) patterns of children's leisure and media activities in respect of parents' educational and social profile. Specifically, more parents with a high autonomy job $(13 \%)\left(\mathrm{X}^{2}=10.057, \mathrm{df}=1, \mathrm{p}=0.02, \mathrm{Phi}=0.171\right)$ responded that their children rarely/ never watch television than parents with a low autonomy job (4\%). Additionally, more parents with a low autonomy job (5\%) $\left(\mathrm{X}^{2}=4.716, \mathrm{df}=1, \mathrm{p}=0.03, \mathrm{Phi}=0.117\right)$ reported that their children rarely/ never make a drawing or write something than parents with a high autonomy job (1\%). Moreover, parents of elementary school education did not report that their children rarely/ never play video games (Estimate $=1.563$, Std. Error=0.742, Z=-2.105, p=0.04). On the other hand, more parents doing a high autonomy job $(14 \%)\left(\mathrm{X}^{2}=5.854, \mathrm{df}=1, \mathrm{p}=0.02, \mathrm{Phi}=0.132\right)$ reported that their children use a computer in children's room than parents with a low autonomy job (6\%). Furthermore, parents with an elementary school education reported that their children do not play in children's room (Estimate=1.999, Std. Error=0.768, $\mathrm{Z}=-2.603, \mathrm{p}=0.009$ ), but that they play in the living room/ other room (Estimate $=-1.948$, Std. Error=0.910, $\mathrm{Z}=-2.141$, $\mathrm{p}=0.03)$.

\subsubsection{Children's Reading and Television Preferences}

According to parents, their children prefer being mostly read fairy tales (90\%) and picture books (80\%), and less educational books $(31 \%)$ or comics (15\%) (Table 7). Moreover, according to chi-square test analysis, a preference for fairy tales is positively correlated with a preference for picture books $\left(\mathrm{X}^{2}=21.24, \mathrm{df}=1, \mathrm{p}=0.00, \mathrm{Phi}=0.241\right)$, whereas a preference for educational books is negatively correlated with a preference for comics $\left(X^{2}=5.396, d f=1, p=0.02\right.$, Phi=-0.121). However, only $3 \%$ of the children reported to prefer being read educational books and another $3 \%$ that they like to be read Greek mythology, while $23 \%$ of the children responded that they like to be read comics. However, both parents and children converged about the latter's most favorite book. The titles mentioned by both groups were mainly drawn either from famous fairy tales (e.g. The Three Little Pigs, The Little Red Riding Hood, Snow White), or from popular cartoon television programs/ films (e.g. Cars-McQueen, Barbie, Winx Club, Disney Princesses, SpongeBob Square Pants).

Table 7. Children's reading preferences (parents' responses)

\begin{tabular}{ll}
\hline Fairy tales & $90 \%$ \\
Picture books & $80 \%$ \\
Educational books & $31 \%$ \\
Comics & $15 \%$ \\
Magazines & $3 \%$ \\
\hline
\end{tabular}

Chi-square test and multivariate log-linear analysis indicated significant differences in children's reading preferences in respect of parents' educational and social profile, revealing the greater orientation of more privileged families to print and more school-like literacy practices. Specifically, more parents who do a high autonomy job $(88 \%)\left(X^{2}=6.530, \mathrm{df}=1\right.$, $\mathrm{p}=0.01$, Phi $=0.139)$ reported that their children prefer being read picture books than parents who do a low autonomy job (77\%). In a similar vein, more parents who do a high autonomy job $(38 \%)\left(\mathrm{X}^{2}=5.214, \mathrm{df}=1, \mathrm{p}=0.02, \mathrm{Phi}=0.124\right)$ reported that their children prefer being read educational books than parents who do a low autonomy job (27\%). Moreover, more children whose mother does a high autonomy job $(88 \%)\left(\mathrm{X}^{2}=4.027, \mathrm{df}=1 \mathrm{p}=0.05, \mathrm{Phi}=0.094\right)$ responded that they like to be read fairy tales than children with a mother doing a low autonomy job (81\%). Similarly, parents of elementary (Estimate $=1.394$, Std. Error=0.726, $Z=-1.920, p=0.05)$ or high school education $($ Estimate=0.649, Std. Error=0.294, $\mathrm{Z}=-2.210, \mathrm{p}=0.03$ ) reported that their children do not prefer being read picture books, while parents with a high school education reported that their children do not prefer being read educational books $($ Estimate $=0.616$, Std. Error=0.233, Z=-2.649, p=0.008).

On the other hand, from children's responses, some significant gender differences emerged with respect to boys' and girls' reading preferences. Specifically, more girls $(87 \%)\left(\mathrm{X}^{2}=4.027, \mathrm{df}=1 \mathrm{p}=0.05, \mathrm{Phi}=0.094\right)$ than boys $(80 \%)$ reported to prefer being read fairy tales. In contrast, more boys $(29 \%)\left(\mathrm{X}^{2}=8.058, \mathrm{df}=1 \mathrm{p}=0.05\right.$, Phi $\left.=-0.133\right)$ than girls $(17 \%)$ reported to like to be read comics. Additionally, more boys $(5 \%)\left(X^{2}=4.059, \mathrm{df}=1 \mathrm{p}=0.04\right.$, Phi $\left.=-0.094\right)$ than girls $(1 \%)$ 
responded that they prefer being read Greek mythology.

Regarding children's favorite television programs, parents reported that their children like to watch mostly cartoons (94\%), and less, documentaries (42\%), movies (31\%) entertainment programs like television shows and quizzes (23\%), and TV series (21\%) (Table 8). Interestingly, none of the children mentioned that they like to watch documentaries, while $76 \%$ of the children reported to watch movies, $70 \%$ of them to watch TV commercials and $62 \%$ of them to watch TV series. However, both parents and children, when asked to report the latter's most favorite TV program, they referred to famous cartoons, like Barbie, Cars-McQueen, Peppa Pig, Dora the Explorer, Le Petit Nicolas, Winx Club, but also some adult Greek TV series like The Kings and The Hara's Café.

Table 8. Children's television preferences (parents' responses)

\begin{tabular}{ll}
\hline Cartoons & $94 \%$ \\
Documentaries & $42 \%$ \\
Movies & $31 \%$ \\
Entertainment programs (TV shows, TV quizzes) & $23 \%$ \\
TV series & $21 \%$ \\
Sports & $14 \%$ \\
News & $1 \%$ \\
\hline
\end{tabular}

Chi-square test and revealed some significant differences in children's TV favorites regarding the social background of the family. Specifically, more parents with a low autonomy job $(28 \%)\left(\mathrm{X}^{2}=4.796, \mathrm{df}=1, \mathrm{p}=0.03\right.$, Phi=-0.119) reported that their children like to watch entertainment programs than parents with a high autonomy job (18\%). Moreover, more children with a mother doing a low autonomy job $(75 \%)\left(\mathrm{X}^{2}=4.977, \mathrm{df}=1 \mathrm{p}=0.03, \mathrm{Phi}=-0.108\right)$ responded that they like to watch TV commercials than children with a mother doing a high autonomy job (65\%).

\subsection{Children's and Parents' Stance and Views on Media}

\subsubsection{Children's Immersion in Media}

Both parents and children reported that the latter have a favorite popular cultural hero, who is a character from children's favorite cartoon television programs/ films, toys, comics or fairy tales. Boys' hero is a 'masculine' character like Superman, Spiderman, McQueen and Ben 10, while girls opt for a more 'feminine' character like Barbie, Winx-Fairies and Snow White. However, more boys $(83 \%)\left(\mathrm{X}^{2}=36.490, \mathrm{df}=1 \mathrm{p}=0.00\right)$ than girls $(57 \%)$ reported to have some favorite popular cultural hero.

According to parents, their children own several icons and items from their favorite popular cultural hero, mostly involving print media (64\%), decorative items (58\%) and clothes/ shoes (51\%) (Table 9). However, it seems that children usually possess a variety of different items from their media and popular cultural idols, judging from chi-square test analysis, which revealed multiple positive correlations between different media item categories: decorative items were correlated with clothes/ shoes $\left(X^{2}=30.627, \mathrm{df}=1, \mathrm{p}=0.000, \mathrm{Phi}=0.289\right)$, as well as with printed material $\left(\mathrm{X}^{2}=12.088\right.$, $\mathrm{df}=1, \mathrm{p}=0.01, \mathrm{Phi}=0.182)$ and food $\left(\mathrm{X}^{2}=7.879, \mathrm{df}=1, \mathrm{p}=0.05\right.$, $\left.\mathrm{Phi}=0.147\right)$; clothes/ shoes were correlated with print media $\left(X^{2}=4.104, \mathrm{df}=1, \mathrm{p}=0.04\right.$, Phi $\left.=0.106\right)$ and with food $\left(\mathrm{X}^{2}=12.386, \mathrm{df}=1, \mathrm{p}=0.000\right.$, Phi $\left.=0.184\right)$; print media were correlated with video games and toys $\left(\mathrm{X}^{2}=6.554, \mathrm{df}=1, \mathrm{p}=0.01, \mathrm{Phi}=0.134\right) .64 \%$ of the children also reported to possess items from their favorite hero, mostly toys (28\%) and clothes/ shoes (22\%).

Table 9. Children's ownership of media icons/ items (parents' responses)

\begin{tabular}{ll}
\hline Books/ comics/ magazines & $64 \%$ \\
Decorative items (e.g. curtains, stickers) & $58 \%$ \\
Clothes/ shoes & $51 \%$ \\
Video games/ toys & $36 \%$ \\
Food/drinks & $7 \%$ \\
\hline
\end{tabular}

Chi-square test showed some significant differences in children's ownership of media icons/ items with respect to the social profile of families and the gender of the child. More analytically, more parents doing a low autonomy job (67\%) $\left(\mathrm{X}^{2}=11.332, \mathrm{df}=1, \mathrm{p}=0.01, \mathrm{Phi}=-0.183\right)$ responded that their child owns decorative items from their favorite popular cultural character than parents with a high autonomy job (49\%). On the other hand, boys seem to be more immersed in popular culture than girls, since the former reported to a greater extent than the latter to own clothes/ shoes (boys: 15\% vs. girls: $6 \%)\left(\mathrm{X}^{2}=8.231, \mathrm{df}=1, \mathrm{p}=0.04, \mathrm{Phi}=-0.134\right)$ and toys (boys: $22 \%$ vs. girls: $\left.13 \%\right)\left(\mathrm{X}^{2}=5.965, \mathrm{df}=1, \mathrm{p}=0.02\right.$, $\mathrm{Phi}=-0.114)$ from their favorite hero.

\subsubsection{Parents' Views on the Educational Opportunities of Media for Their Children}

The majority of parents (54\%) (strongly/ tend to) believe that all media can help their children's literacy development, but, almost unanimously (97\%), they (strongly/ tend to) agree with the idea that all media can be used at school (Table 10). Nevertheless, a great number of parents (44\%) seem to express a more conservative view that only books can 
motivate their children's literacy skills, while $33 \%$ of the parents (strongly/ tend to) believe that television and computers have a negative effect on their child's education. On the other hand, $89 \%$ of the parents express their concerns about television's consumerist and violent content and $95 \%$ of them (strongly/ tend to) believe that school can protect their children against the dangers of television.

Table 10. Parents' views on the educational value of media

\begin{tabular}{lccccc}
\hline Statements & I strongly agree & $\begin{array}{c}\text { I tend to } \\
\text { agree }\end{array}$ & $\begin{array}{c}\text { I strongly } \\
\text { disagree }\end{array}$ & $\begin{array}{c}\text { I tend to } \\
\text { disagree }\end{array}$ & I don't know \\
\hline 1 & $37 \%$ & $27 \%$ & $16 \%$ & $18 \%$ & $2 \%$ \\
2 & $81 \%$ & $16 \%$ & $1 \%$ & $1 \%$ & $1 \%$ \\
3 & $13 \%$ & $20 \%$ & $27 \%$ & $35 \%$ & $5 \%$ \\
4 & $22 \%$ & $22 \%$ & $19 \%$ & $36 \%$ & $1 \%$ \\
6 & $69 \%$ & $20 \%$ & $4 \%$ & $6 \%$ & $1 \%$ \\
\hline
\end{tabular}

Note: 1. Books, television and computers motivate my child to learn to read/ write, 2. Books, television and computers can be used for educational purposes at school, 3. Television and computers are harmful to my child's education, 4. Only books help my child to learn to read/ write, 5. I'm concerned about the negative effects of television advertising and violence on my child, 6. Discussion about television with teacher at school can protect my child against the harmful effects of television advertising and violence.

To ordinate parents' responses, a PCA was used. Two factors were extracted, accounting for $53 \%$ of the total variance. As we can see in Table 11, the first factor accounts for $35 \%$ of the total data variability and is marked by high loadings on items that stress polar ideas about the role of media in education. Specifically, in Factor 1, two contrastive subgroups were made between more progressive (Statements 1 and 2) and more conservative (Statements 3, 4, and 5) cognitive and affective attitudes towards the educational role of media. On the other hand, Factor 2, which explains $18 \%$ of the total data variability, refers to hypothetical reasoning supporting the introduction of media to school and expressing a more moderate view on the educational role of media by attempting to reconcile the two contrasting poles of Factor 1.

Table 11. Principal component analysis of parents' responses about their views on the educational value of media

\begin{tabular}{lcc}
\hline Statements & Factor 1 & Factor 2 \\
\hline 1 & 0.754980 & 0.046542 \\
2 & 0.505888 & -0.433210 \\
3 & -0.702814 & -0.282998 \\
4 & -0.781155 & -0.175901 \\
5 & -0.391864 & -0.057406 \\
6 & 0.202611 & -0.862626 \\
Expl. Var & 2.124677 & 1.048285 \\
Prp. Totl & 0.354113 & 0.174714 \\
\hline
\end{tabular}

Note: 1. Books, television and computers motivate my child to learn to read/ write, 2. Books, television and computers can be used for educational purposes at school, 3. Television and computers are harmful to my child's education, 4. Only books help my child to learn to read/ write, 5. I'm concerned about the negative effects of television advertising and violence on my child, 6. Discussion about television with teacher at school can protect my child against the harmful effects of television advertising and violence.

Multivariate log-linear analysis revealed some correlations between parents' responses about their children's daily patterns of media use (see Table 4) and their views on the educational value of media (Table 10). Specifically, children's book reading for 1-2 hours a day is negatively correlated with parents' ignorance (Estimate=-3.949, Std. Error=1.827, $\mathrm{Z}=-2.142, \mathrm{p}=0.03$ ) about the educational use of books, television and computers (Statement 2). Moreover, children's computer use for 1-2 hours a day is negatively correlated with parents' ignorance (Estimate $=-4.244$, Std. Error=2.162, $\mathrm{Z}=-1.963, \mathrm{p}=0.05$ ) and disagreement (Estimate $=-5.342$, Std. Error $=1.828, \mathrm{Z}=-2.922, \mathrm{p}=0.03$ ) about the educational use of books, television and computers (Statement 2). Finally, children's never/ rarely playing outside is positively correlated with parents' disagreement (Estimate $=2.277$, Std. Error=1.048, Z=2.173, $p=0.03$ ) about the harmful effects of television and computer on their children's education (Statement 3 ).

Chi-square test and multivariate log-linear analysis showed some significant differences in parents' views on the educational role of media with respect to their social and educational background. Largely, these differences indicate that less privileged families, which are more oriented to screen entertainment leisure and media activities and less oriented to print and digital ones, are, however, more negative about the educational value of these media. Specifically, more parents who do a low autonomy job $(25 \%)\left(\mathrm{X}^{2}=12.161, \mathrm{df}=4, \mathrm{p}=0.02, \mathrm{Phi}=0.183\right)$ strongly agree that only books enhance their children's literacy skills (Statement 4) than parents who do a high autonomy job (15\%). Similarly, parents of elementary (Estimate=-2.082, Std. Error=0.976, Z=-2.133, p=0.03) or of high school education (Estimate=-0.664, Std. Error $=0.313, \mathrm{Z}=-2.121, \mathrm{p}=0.03$ ) agree that only books can contribute to their children's literacy development (Statement 
4). Furthermore, parents with an elementary school education are ignorant about the supposed superiority of books on children's literacy over other media (Statement 4) (Estimate $=3.173$, Std. Error=1.634, Z=1.943, p=0.05). On the other hand, more parents who do a low autonomy job $(15 \%)\left(\mathrm{X}^{2}=10.352, \mathrm{df}=4, \mathrm{p}=0.04, \mathrm{Phi}=0.176\right)$ strongly agree that television and computers are harmful to their children's education (Statement 3 ) than parents who do a high autonomy job (8\%). Finally, parents of elementary school education are ignorant whether all media, including television, books and computers, contribute to their children's literacy development (Statement 1) (Estimate $=4.268$, Std. Error=1.756, $\mathrm{Z}=2.431, \mathrm{p}=0.02$ ).

\section{Discussion}

In the present paper, we attempted to map Greek young children's engagement with media in the home, through an account of children's and parents' perspectives. From the analysis of interviews with children and questionnaires with parents, it was made clear that children have rich media experiences in the home, having access to print (books, comics, magazines), screen entertainment (television, DVD) and digital media (computers), whereas the presence of video games in Greek homes is more limited compared with other countries, such as the UK (Marsh et al., 2005) and Spain (Bringué \& Sádaba, 2009a). Moreover, children go often to the movies and sometimes to the theater with their parents. Although printed texts prevail in children's bedrooms, and book reading seems to be a widespread activity in most families, screen entertainment and digital media are central to the lives of all family members. Thus, half of the children responded to own two television sets and reported that all family members use a computer. However, contrary to the wide held idea that there is supposedly an 'antagonistic' relationship between digital and print media, our research indicated that a home open to new technologies tends to be 'media rich' in general. Similarly, a greater access of children to the movies was knitted to a greater access to the theater as well.

Regarding the daily program of children on leisure and media activities in the home, it seems that this mainly consists of traditional (drawing/ writing, playing with toys in the home, book reading) and conventional screen entertainment media activities (television watching). In contrast, other screen entertainment (DVD watching, video game playing) and digital media activities (computer use) are less common among children. Interestingly, a traditional leisure activity among children, such as outdoor play, seems also to be less popular among today's children. This could be probably attributed to the observing attenuation of the outdoor culture and the increasing gaining of the bedroom culture in Greek society, due to parents' worries about letting their children stay outdoors unsupervised (Tsaliki, 2009). In their room, children usually play and are read some book. In contrast, television/ DVD watching and computer use seldom take place in their room, but are activities which commonly occur in spaces which are shared by all family members. With respect to children's reading preferences, our study showed that these mostly include 'standard' choices, such as classic fairy tales and picture books, while children who prefer comics usually dislike educational books. In contrast, their television preferences concern both children's (cartoons) and adult TV programs (TV series, movies, TV shows and quizzes).

From both parents' and children's responses, it was evident that media icons have a central role in children's lives, as confirmed also by other studies (e.g. Marsh et al., 2005). Most children have some favorite popular cultural hero, who is usually a character from the books they read and the television programs they watch, while these media icons are also present in their clothes, shoes and toys.

Parents seem to be affected by the 'moral panics' often surrounding young children's use of media, involving concerns about the supposed negative impact of media on children's emotional and social development (Kenway \& Bullen, 2001). Specifically, they looked worried about the content of television programs their children watch and some of them even considered that television and computers are harmful for children. Furthermore, they appeared divided whether all media or only books contribute to their children's literacy development. Therefore, most of the parents were favorable with the idea of media education, viewing it as a means of preventing children from the 'harmful' media messages. In this way, they adhered to an 'inoculation' model of media education (Buckingham, 2004), according to which media education is seen as a protective 'shield' against negative media content. Interestingly, parents' views on the educational role of media tended to be in accordance with their children's practices. Thus, children whose parents have positive views on the educational role of computers and books are more likely to spend an important amount of time daily using those media.

These findings diverge from relevant research which has shown that, although parents often raise some concerns about the quality of media content (Livingstone \& Bovill, 1999; Ofcom., 2013), they tend to be generally favorable about the role of media in their children's social, linguistic and emotional development (Livingstone \& Bovill, 1999; Marsh et al., 2005; Rideout et al., 2003). This could be probably attributed to the fact that media have been only recently introduced to the Greek curriculum in a systematic way (Greek Ministry of Education, 2011) in comparison with the UK (in which most of the studies have been situated), which has a long history in media literacy and education. In fact, in contrast to USA, in which an 'inoculation' model of media education has developed, in the UK, media education is based on the notion of 'cultural understanding', concerning a close and critical analysis of media messages and representations of social reality (Buckingham, 2004).

The analysis of both parents' and children's reports on the latter's media activities in the home indicated several 
significant differences with respect to the social status of parents. Specifically, our study indicated that families with a more privileged social and educational background seem to be more oriented to print and digital media than families with a lower social status, by having access and using more books and computers. In contrast, families of lower social and educational background tend to be more oriented to screen entertainment media, by having more frequently a television set in the children's room, by being more likely to own a DVD player and by having their children play more video games than families of higher social status. These findings have been largely confirmed by previous studies, not only in the UK (Livingstone \& Bovill, 1999; Ofcom., 2013; Marsh et al., 2005) and other European countries (Mascheroni \& Cuman, 2014), but also in Greece (Koutsogiannis, 2011; Stamou et al., 2013; Tsami et al., 2014).

However, the present study also revealed that the spatial autonomy of children's media and leisure activities from the wider home environment is probably bigger in more privileged families, in which children seem to spend more time in their room for these activities, than children from a less privileged social background. Moreover, families with a higher social status seem to go more often their children to the theater and the movies. Conversely, families of a lower social and educational background tend to be more immersed in popular culture, since their children own more media icons, but also they tend to allow to a greater extent their children to play outdoors than children from families of higher social status. Hence, irrespectively of whether these differences are only due to available financial resources (e.g. whether less privileged families cannot afford having an extra room for their children, or cannot pay the tickets for the theater and the movies, and promote instead 'cheap' leisure activities for their children, such as outdoor play), or are probably more an issue of parents' educational and cultural resources (e.g. whether they consider important or not the spatial autonomy of their children, whether they consider or not that outdoor play is unsafe for contemporary children), in any case, they advocate that more privileged families prioritize school-like literacy practices to greater extent in comparison with less privileged ones.

Interestingly, despite the fact that parents of lower educational and social background tend to prioritize screen entertainment media in the home, they seem to hold more negative views on their educational role, by supporting to a greater extent than parents of higher educational and social background that only books can contribute to their children's literacy development, or that television and computers are harmful to their children's education. This inconsistency between their views and practices could be attributed to the fact that parents of lower social status are probably more susceptible to 'moral panics' about media and less familiar with contemporary approaches to school literacy.

Our study also disclosed some significant differences with respect to the children's gender. Girls seem to show a greater preference for the reading of fairy tales, while boys mainly like being read comics and Greek mythology. Moreover, girls have different favorite popular cultural characters than boys, mostly drawing upon classic fairy tales and 'feminine' cartoon characters. In contrast, boys' favorite heroes come from famous superheroes and 'masculine' cartoon characters. These differences between boys and girls regarding their preferences for media, which are largely confirmed by previous research (e.g. Livingstone \& Bovill, 1999), seem to be linked to the social expectations and the distinct social roles of what means to 'be a girl' and 'a boy'. In a similar attempt to construct a 'masculine' identity, it was also found that more boys than girls show an interest for video games and popular culture. Except for the fact that several studies (Bringué \& Sádaba, 2009a; 2009b; Livingstone \& Bovill, 1999; Ofcom., 2013; Marsh et al., 2005; Rideout et al., 2003) -including Greece (Tsaliki \& Chronaki, 2012) - have indicated that video game playing is a largely gendered activity, these choices on the part of boys seem to suggest that they are less familiar than girls with school-like literacy practices. This finding is in tune with sociolinguistic studies which have shown that boys tend to follow to a lesser degree than girls the conventions of school discourse (Hamstra-Bletz \& Blöte, 1990; Griva, Semoglou, \& Panteli, 2009; Stamou, Griva, \& Demetriou, 2013).

The abovementioned results of the present study raise important implications for the role of family in children's schooling. Specifically, it is suggested that traditional school, which promotes print literacy practices, is highly possibly to exclude students coming from families of lower social status and boys, who prioritize popular culture and screen entertainment media, namely non-school-like activities. In light of this, the introduction of media texts to many school curricula worldwide (Duff, 2004), recently also systematically introduced to Greek education (Greek Ministry of Education, 2011), can contribute to the bridging of these social inequalities. However, given the fact that less privileged families have limited access to digital media as well, contemporary educational systems, which have, often unproblematically, introduced new technologies, should attempt to bridge the digital gap still existing for many students. On the other hand, in order for such an education endeavor to succeed in countries, such as Greece, with no tradition in the institutionalization of media literacy, both parents' (as shown by the present study) and teachers' (Maroniti \& Stamou, 2014) views on the notion of school literacy should change, through systematic information and training of both stakeholders.

Finally, from a methodological perspective, in the present study, we acknowledged the limitations of (self)-reporting of children's media activities in the home, and thus we explored both parents' and children's perspectives, treating the two groups not only as providing complementary but also contradictory accounts of children's home engagement with media. In this view, we detected some instances of over-/ under-reporting between the two groups. Some of them could be probably ascribed to the fact that young children are not able to calculate the time, and thus they cannot, for example, 
accurately report how 'often' they go to the theater. However, most of the inconsistencies observed between parents' and children's reports seem to be due to the so-called 'social desirability bias' (McBurney, 1994) on the part of parents. For example, while almost half of the parents reported that their children like to watch documentaries, none of the children included documentaries to their television preferences. Similarly, much fewer parents reported that their children prefer watching adult programs like TV series, in comparison with children. Interestingly, probably again under the influence of the social desirability bias, parents responded differently even to the same question in different parts of the questionnaire. For example, when parents reported the daily patterns of their children's activities tended to over-report that their children rarely/ never watch television in comparison with their responses when they determined the spatial distribution of this activity. In conclusion, we suggest that a study including both the perspectives of parents and children on the latter's media activities in the home can better address the limitations of (self)-reporting and complement observational studies of literacy practices.

\section{Acknowledgements}

This research was conducted in the context of the Operational Program Education and Lifelong Learning, co-funded by the EU (European Social Fund) and by national resources.

\section{References}

Ball, S., \& Bogatz, G. A. (1970). The first year of 'Sesame Street': An evaluation. Princeton, NJ: Educational Testing Service.

Bringué, X., \& Sádaba, C. (2009a). The interactive generation in Spain: Children and adolescents faced with the screens. Executive Summary. Retrieved from http://www.generacionesinteractivas.org/upload//libros/Executive-The-Interactive-Generations-in-Spain.pdf

Bringué, X., \& Sádaba, C. (2009b). Interactive generations in Ibero-America: Children and adolescents faced with the screens. Executive Summary. Retrieved from http://www.generacionesinteractivas.org/upload/libros/Executive\%20Summary\%20Ibero-America.pdf

Buckingham, D. (2004). The media literacy of children and young people. A review of the research literature of behalf of Ofcom. London: Ofcom. Retrieved from http://eprints.ioe.ac.uk/145/1/Buckinghammedialiteracy.pdf.

Duff, P. A. (2004). Intertextuality and hybrid discourses: The infusion of pop culture in educational discourse. Linguistics \& Education, 14, 231-276. http://dx.doi.org/10.1016/j.linged.2004.02.005

Gee, J. P. (1996). Social linguistics and literacies: Ideology in discourses (2nd ed.). London: Falmer Press.

Greek Ministry of Education (2011) (in Greek). New school-New school curriculum: Teacher's guide for the curriculum of pre-school education. Retrieved from http://dschool.edu.gr/

Griva E, Semoglou K, \& Panteli, P. (2009). Gender, genre variation and young writers: Detecting stereotype effects. International Journal of Learning, 16, 327-343.

Gutiérrez, K., Baquedano-Lopez, P., \& Tejeda, C. (2000). Rethinking diversity: Hybridity and hybrid language practices in the third space. Mind. Culture, \& Activity: An International Journal, 6(4), 286-303. http://dx.doi.org/10.1080/10749039909524733

Haddon, L., \& Livingstone, S. (2012). EU Kids Online: National perspectives. London: London School of Economics and Political Science. Retrieved from http://eprints.lse.ac.uk/46878

Haddon, L. (2011). Domestication analysis, objects of study, and the centrality of technologies in everyday life. Canadian Journal of Communication, 36(2), 311-323.

Hamstra-Bletz, L, \& Blöte, A. W. (1990). Developmental of handwriting in primary school: A longitudinal study. Perceptual and Motor Skills, 70, 759-770. http://dx.doi.org/10.2466/pms.1990.70.3.759

Hasan, R. (1989). Semantic variation and sociolinguistics. Australian Journal of Linguistics, 9, $221-275$. http://dx.doi.org/10.1080/07268608908599422

Holloway, D., Green, L., \& Livingstone, S. (2013). Zero to eight. Young children and their internet use. London: London School of Economics and Political Science. Retrieved from http://eprints.1se.ac.uk/52630/1/Zero_to_eight.pdf

Hull, G., \& Schultz, K. (2001). Literacy and learning out of school: A review of theory and research. Review of Educational Research, 71(4), 575-611. http://dx.doi.org/10.3102/00346543071004575

Kenway, J., \& Bullen, E. (2001). Consuming children: Education-entertainment-advertising. Buckingham: Open University Press.

Koutsogiannis, D. (2011) (in Greek). Digital literacy practices and identities. Thessaloniki: Center of Greek Language.

Linebarger, D. L., \& Piotrowski, J. T. (2009). TV as storyteller: How exposure to television narratives impacts at-risk preschoolers' story knowledge and narrative skills. British Journal of Developmental Psychology, 27, 47-69. http://dx.doi.org/10.1348/026151008X400445 
Livingstone, S., \& Bober, M. (2005). UK children go online. Final report of key project finding. London: London School of Economics and Political Science. http://eprints.lse.ac.uk/399/1/UKCGO_Final_report.pdf

Livingstone, S., \& Bovill, M. (1999). Young people, new media: Report of the research project 'Children Young People and the Changing Media Environment'. London: London School of Economics and Political Science. Retrieved from http://eprints.lse.ac.uk/21177/1/Young_people_new_media_(LSERO).pdf

Maroniti, K., \& Stamou, A. G. (2014) (in Greek). Exploration of the teachers' ideas about the use of mass cultural texts in language education. Proceedings of the 34th Meeting of the Department of Linguistics (pp. 271-284). Thessaloniki: Idryma Manoli Triantafyllidi.

Marsh, J., \& Millard, E. (2000). Literacy and popular culture: Using children's culture in the classroom. London: Paul Chapman/ Sage.

Marsh, J. (2003). One-way Traffic? Connections between literacy practices at home and in the nursery. British Educational Research Journal, 29(3), 369-382. http://dx.doi.org/10.1080/01411920301857

Marsh, J. (Ed.) (2005). Popular culture, media and digital literacies in early childhood. London: Routledge. http://dx.doi.org/10.4324/9780203420324

Marsh, J., Brooks, G., Hughes, J., Ritchie, L., Roberts, S., \& Wright, K. (2005). Digital beginnings: Young children's use of popular culture, media and new technologies. University of Sheffield: Literacy Research Center. Retrieved from http://www.digitalbeginnings.shef.ac.uk/DigitalBeginningsReport.pdf

Mascheroni, G., \& Cuman, A. (2014). Net Children Go Online. Final Report. Milano: Educatt. Retrieved from http://www.netchildrengomobile.eu

Miles, M. B., \& Huberman, A. M. (1994). Qualitative data analysis (2nd ed.). Thousand Oaks, CA: Sage.

Morgeson, F. P., Delaney-Klinger, K. A., \& Hemingway, M. A. (2005). The importance of job autonomy, cognitive ability, and job-related skill for predicting role breadth and job performance. Journal of Applied Psychology, 90, 399-406. http://dx.doi.org/10.1037/0021-9010.90.2.399

Ofcom. (2013). Children and parents: Media use and attitudes report. Retrieved from http://stakeholders.ofcom.org.uk/binaries/research/media-literacy/october-2013/research07Oct2013.pdf

Reay, D. (1998). Class work: Mothers' involvement in their children's primary schooling. London: UCL Press.

Rideout, V. J., Vandewater, E. A., \& Wartella, E. A. (2003). Zero to six: Electronic media in the lives of infants, toddlers and preschoolers. Washington: Kaiser Foundation.

Silverstone, R., \& Haddon, L. (1996). Design and the domestication of ICTs: Technical change and everyday life. In R. Silverstone \& R. Mansell (Eds), Communication by design: The Politics of information and communication technologies (pp. 44-74). Oxford: Oxford University Press.

Stamou A. G., Griva E., \& Demetriou, M. (2013). School language and gender: Evidence from Greek speaking primary school students' writings. Proceedings of the International Conference 'Sociolinguistic Studies in Albania: Achievements, Current State and Perspectives' (pp. 132-137). Korce: University of Korce.

Stamou A. G., Griva, E., \& Tsioulis, A. (2013) (in Greek). The out-of-school literacy practices of primary school children: A record of their ideas and preferences. In N. Tsitsanoudi-Mallidi (Ed.), Language and contemporary (early) school education (pp. 304-339). Athina: Gutenberg.

Street, B. V. (1993). The New Literacy Studies: Guest editorial. Journal of Research in Reading, 16(2), 81-97. http://dx.doi.org/10.1111/j.1467-9817.1993.tb00039.x

Tsaliki, L., \& Chronaki, D. (2012) (in Greek). Children and the Internet in Greece-GRKGO. Research project funded from General Secretariat of Youth. Athens: National Kapodistrian University of Athens, Department of Communication and Mass Media. Retrieved from http://www2.media.uoa.gr/people/tsaliki/wp-content/uploads/2010/07/Tsaliki_Kids_and_Internet_in_Greece.pdf

Tsaliki, L. (2009). National report for Greece: EU Kids Online. Retrieved from http://www.lse.ac.uk/media@1se/research/EUKidsOnline/EU\%20Kids\%20I\%20(2006-9)/EU\%20Kids\%20Online $\% 201 \% 20$ Reports/WP3NationalReportGreece.pdf

Tsami, V., Archakis, A., Fterniati, A., Papazachariou, D. \& Tsakona, V. (2014). Mapping elementary school students' preferences for mass cultural literacy practices. Proceedings of the International Conference 'Education across Borders' (pp. 361-371). Florina: School of Education, University of Western Macedonia. Retrieved from http://www.edu.uowm.gr/site/sites/default/files/crossborder_proceedings_2012_issn.pdf

This work is licensed under a Creative Commons Attribution 3.0 License. 